Document downloaded from:

http://hdl.handle.net/10251/60427

This paper must be cited as:

Bermúdez, V.; Pastor Soriano, JV.; López, JJ.; Campos, D. (2014). Experimental correlations for transient soot measurement in diesel exhaust aerosol with light extinction, electrical mobility and diffusion charger sensor techniques. Measurement Science and Technology. 25(6):1-13. doi:10.1088/0957-0233/25/6/065204.

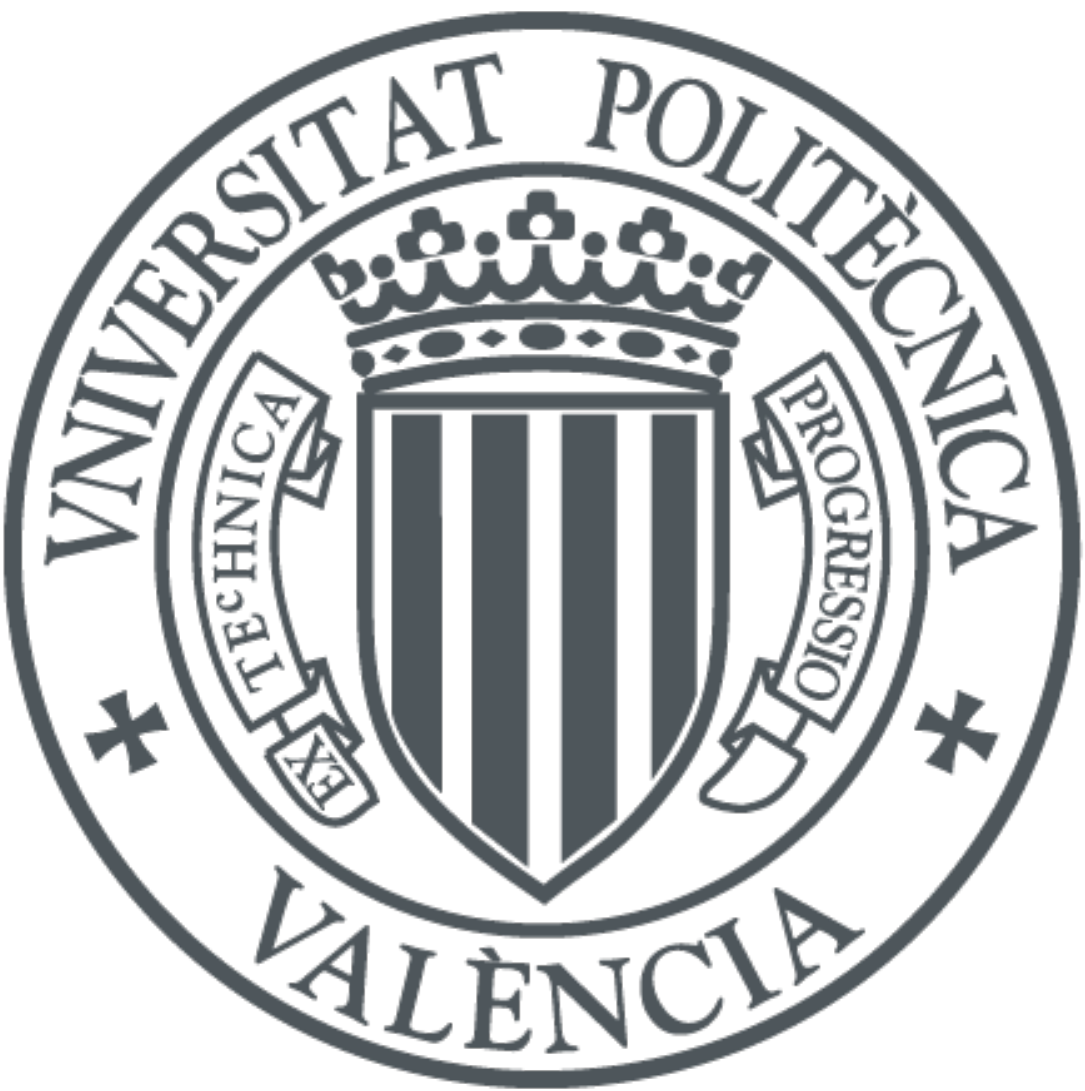

The final publication is available at

http://dx.doi.org/10.1088/0957-0233/25/6/065204

Copyright IOP Publishing: Hybrid Open Access

Additional Information 


\title{
Experimental correlations for transient soot measurement in diesel exhaust aerosol with light extinction, electrical mobility and diffusion charger sensor techniques
}

\author{
Vicente Bermúdez, José Vicente Pastor, José Javier López, \\ Daniel Campos \\ CMT-Motores Térmicos, Universitat Politècnica de València, Camino de Vera s/n, \\ 46022, Valencia, Spain \\ E-mail: bermudez@mot.upv.es
}

\begin{abstract}
.
A study of soot measurement deviation using a diffusion charger sensor with three dilution ratios enables was conducted in order to obtain a repeatable setting that can be used to obtain measurements of the particulate matter in terms of soot mass emitted by a light-duty diesel engine under transient operating conditions. The paper includes three experimental phases: an experimental validation of the measurement settings in steady-state operating conditions; evaluation of the proposed setting under the New European Driving Cycle, and a study of the correlations for different measurement techniques providing reliable correlations for estimating soot emission from opacity measurement or from accumulation particle mode concentration. There are several methods and correlations to estimate soot mass rate in the literature but most of them were assessed for steady-state operating points. In this case, the correlations are obtained by more than 4000 points measured in transient conditions. The results of soot measurements allowed by the new two correlations and deviations less that $4 \%$ to the reference measurement founded in both correlations are presented in this paper.
\end{abstract}

Keywords: Diesel engine, soot emission, optical techniques, electrical mobility techniques, correlations 


\section{Nomenclature}

$\begin{array}{ll}\text { Symbols } & \\ A_{t o t} & \text { Total active surface area } \\ A c \cdot \text { conc. } & \text { Accumulation particle concentration } \\ C & \text { Cunningham correction factor } \\ d n / d t & \text { Decrease in the ion concentration } \\ D_{p} & \text { Particle diameter } \\ e_{c} & \text { Elementary charge } \\ I & \text { Transmitted light intensity } \\ I_{0} & \text { Incident light intensity } \\ I_{c} & \text { Electrometer current } \\ I_{D C S} & \text { Diffussion charger sensor current } \\ k & \text { Light extincion coefficient } \\ k T & \text { Boltzman constant } \\ K & \text { Coefficient for particle }[1] \\ L & \text { Opacimeter measurement chamber length } \\ m_{i o n} & \text { Electric ions mass } \\ n & \text { Ion concentration } \\ n_{c} & \text { Particle charges number } \\ N & \text { Opacity } \\ N_{\text {pol. }} & \text { Polydisperse aerosol concentration } \\ S o o t & \text { Soot concentration } \\ Z_{p} & \text { Electrical mobility } \\ \mu & \text { Gas viscosity } \\ & \end{array}$




$\begin{array}{ll}\text { Abbreviations } & \\ \text { AFR } & \text { Air to fuel ratio } \\ \text { CAD } & \text { Cranck angle degree } \\ \text { DCS } & \text { Diffusion Charging Sensor } \\ \text { DR } & \text { Dilution Ratio } \\ \text { ECU } & \text { Electronic Control Unit } \\ \text { ED } & \text { Ejector diluter } \\ \text { EEPS } & \text { Engine Exhaust Particle Sizer } \\ \text { EGR } & \text { Exhaust Gas Recirculated } \\ \text { EUDC } & \text { Extra Urban Driving Cycle } \\ \text { FPS } & \text { Fine Particle Sampler } \\ \text { HACA } & \text { Hydrogen Abstraction-aCetylene Addition } \\ \text { HSDI } & \text { High Speed Direct Injection } \\ \text { ISF } & \text { Insoluble Fraction } \\ \text { NEDC } & \text { New European Driving Cycle } \\ \text { PAH } & \text { Polycyclic Aromatic Hydrocarbon } \\ \text { PM } & \text { Particulate Matter } \\ \text { PN } & \text { Particle Number } \\ \text { PTD } & \text { Porous Diluter Tube } \\ \text { PSD } & \text { Particle size distribution } \\ \text { SOF } & \text { Soluble Organic Fraction } \\ \text { SOI } & \text { Start Of Injection } \\ \text { USLD } & \text { Ultra Low Sulfur Diesel }\end{array}$

\section{Introduction}

Nowadays, most important source of environment pollution comes from human sources, most of them being powered vehicles [2]. One of the main causes of cardio-respiratory diseases and negative effects on human health are the particles generated by diesel engines [3, 4]. Due to these respiratory problems, European Union members began to show a strong interest in reducing these emissions, imposing limits on the soot mass emitted by diesel engines [5], and more recently on number of particles $(P N)$ emitted [6]. Currently, many researchers are giving knowledge about diesel aerosol and particles morphology in the exhaust gas $[7,8]$. Exhaust particulate matter $(P M)$ is defined as any solid or liquid material, except water, trapped in a filter material at a given temperature, and it is mainly composed by insoluble carbonaceous material $(I S F)$ and adsorbed hydrocarbons from fuel or lubricating oil $(S O F)$ [9].

For some time, different standards of the European Union [10] limit soot emission from diesel engines based on the mass of particulate matter quantificated by gravimetric method [11]. The problem associated to this method is the long time necessary to 
collect enough mass in the filters for a representative weighting. Also, volatilization of certain semivolatile compounds which are adsorpted occurs up on the filters during particle collection [12]. In adition, a rigorous methodology for subsequent analysis of soot mass trapped in filters is reqired, since the $S O F$ trapped must be extracted by Soxhlet method [13]. Furthermore, this method only allows quantification of the final filter mass trapped during a period of time, but do not allow the quantification of the instantaneous particulate emission, so it is very difficult for engine calibration to minimize the soot emission in transient operating conditions. Due to this fact, the use of new systems capables to provide transient soot measurement are becoming increasing. In this sense, it is necessary to establish optimum measurement conditions in order to allow transient soot measurements with less posible variations.

Besides filter-based methods, various instruments and methods can be used to measure particle concentration, which are nearly linked to soot mass concentration. Particle sizing instruments can be used to measure particle size distributions. Generally, those instruments are designed to measure the electrical mobility diameter of particles such as the scanning mobility particle sizer [14], or engine exhaust particle sizer [15]. Recent studies have shown that soot present in the exhaust gas is mainly composed by denominated accumulation particle concentration mode [16], so measurement of this kind particle concentration in parallel to soot concentration measurement can give us knowledge of the relationship between these two measurements.

Additionally, for all substances in the particulate matter, soot is recognized as the main compound causing the smoke opacity [17], and therefore opacimeters are generally used to measure this opacity. Nevertheless, opacity in the exhaust gas is not only caused by soot concentration, and some deviation in the measurement is caused by particle morphology and its effect on light scattering [18]. In this sense, other factors such as exhaust gas temperature, flow rate and condensation takes great importance for these conversions [19].

In the literature, numerous authors have attempted to find relationships between different measurement techniques and actual soot mass emission [20, 21]. Due to engine evolution, these relationships are becoming obsolete, and give erroneous estimations of soot mass emitted by modern vehicles. Most of these correlations have been obtained through measurements in steady-state operating points [22], being necessary new correlations for estimate transient soot emission obtained during transient tests.

The aim of this paper is, therefore, to validate the condition measurement in a device used for transient soot emision measurement (diffusion charging sensor) and then, aplying the optimum condition measurement obtained for transient soot measurements, derive empirical correlations between two different measurement techniques which can provide a reliable measurement of the soot mass emission to the users. In this case, related measurement techniques have been both opacity and electrical mobility of the particles, with the soot rate measured directly by a diffusion charger. 


\section{Methodology}

Extensive experimental work has been conducted in order to correlate three different measurement techniques that have been used in this study. Two different test types have been assessed and the methodology used was as follows: firstly, steady-state operating points were performed in order to select the optimun dilution ratio for soot measurement with the difussion charging sensor. After optimun dilution ratio has been determined for soot measurement, different New European Driving Cycles $(N E D C)$ were assessed in order to validate transient soot measurement. Finally, extra urban driving cycle $(E U D C)$ phase was used to correlate different techniqes during transients operations.

\subsection{Optimun dilution ratio selection for soot measurement}

Steady-state operating points have been performed to stablish how dilution stages affect on soot measurement. Three steady-state engine modes (table 1) were assessed in order to generate different particle size distributions and study the dispersion factors produced or not as a result of different aerosol characteristics: in mode named $\mathrm{A}_{(\mathrm{Nuc})}$, particle size distribution was dominated by nucleation mode; mode named $\mathrm{B}_{(\mathrm{Bim})}$ presents bimodal particle size distribution; and mode named $\mathrm{C}_{(\mathrm{Ac})}$ shows particle size distribution dominated by accumulation mode.

Table 1. Steady state operating points for the validation of the soot measurement.

\begin{tabular}{lccccc}
\hline Mode & Speed & Torque & Injection pressure & SOI & AFR \\
\hline & {$[\mathrm{rpm}]$} & {$[\mathrm{Nm}]$} & {$[\mathrm{bar}]$} & {$\left[{ }^{\circ} \mathrm{CAD}\right]$} & {$[-]$} \\
\hline $\mathrm{A}_{(\mathrm{Nuc})}$ & 1500 & 210 & 1100 & -3 & 17.7 \\
$\mathrm{~B}_{(\mathrm{Bim})}$ & 750 & 0 & 250 & -0.50 & 58.7 \\
$\mathrm{C}_{(\mathrm{Ac})}$ & 1660 & 91 & 800 & 0.85 & 21.9 \\
\hline
\end{tabular}

\subsection{Transient soot measurement through three different techniques}

In the sencond part of the study, different $N E D C$ 's were conducted in order to check the instantaneous and accumulated soot measurement during a homologation cycle, and verify that selected dilution ratio was the optimun. After this verification, the $E U D C$ phase of the $N E D C$ was selected to correlated accumulation particle concentration and opacity measurement with the soot measurement performed with the optimun dilution ratio.

In order to obtain good accuracy in the separation of accumulation particle mode, particle size distributions can be decomposed by equation (1). It stablish that total particle size distribution is the sum of both particle mode cocentrations, assuming the log-normal size distribution function: 


$$
\begin{aligned}
\frac{d N_{i}}{d \log d p_{i}} & =\frac{1-x}{\sqrt{2 \pi} \log \sigma_{g 1}} \exp \left[-\frac{\log ^{2}\left(\frac{d p_{1}}{d p_{g 1}}\right)}{2 \log ^{2} \sigma_{g 1}}\right]+ \\
& +\frac{x}{\sqrt{2 \pi} \log \sigma_{g 2}} \exp \left[-\frac{\log ^{2}\left(\frac{d p_{2}}{d p_{g 2}}\right)}{2 \log ^{2} \sigma_{g 2}}\right]
\end{aligned}
$$

In equation (1), $x$ is the ratio of the total number of concentrations of two distributions, $d p_{1}, d p_{2}, \sigma_{g 1}$ and $\sigma_{g 2}$ are the geometric mean diameters and geometric standard deviations of each peak, and $N_{i}$ is the particle number concentration of particle size $d p_{i}$.

Several studies proposed nucleation mode limits between 30 and $50 \mathrm{~nm}$ [23]. In this study, nucleation mode particles was decomposed from 5.6 to $30 \mathrm{~nm}$. Accumulation mode particles was ranged from 30 to $560 \mathrm{~nm}$.

\section{Soot particle formation}

In this section, soot particles formation will be described. It is necessary to state how soot particles are formed due to the fact that the measurement carried out in this study (accumulation particle concentration, opacity, and soot emission rate) are performed by different methods, and they can be affected by the structure of these particles.

It is well known that soot is mainly carbon $(I S F)$ from high temperature combustion and it is produced as an intermediate step between the fuel evaporation and fuel dehydrogenation [24]. The evolution of molecules from vapor-phase or liquidphase to solid soot particles includes phenomena such a pyrolysis, precursor formation, polymerization, nucleation and surface growing [25], as shown in Figure 1.

Firstly, fuel suffers pyrolysis phenomenon due to high temperatures in the combustion chamber, whereby its molecular structure is altered and partially oxidized [26]. Haynes and Wagner determined that $\mathrm{C}_{2} \mathrm{H}_{2}, \mathrm{C}_{2} \mathrm{H}_{4}, \mathrm{CH}_{4}$ and benzene were typical compounds originating from fuel pyrolysis diffusion flames [27]. From this point, aromatic ring formation is due to the attack of $C_{2} H_{2}$ to $n-C_{4} H_{3}$ radicals (at high temperatures) or $n-C_{4} H_{5}$ radicals (at low temperatures). The first ring changes by $H A C A$ process (Hydrogen abstraction-acetylene addition). $H A C A$ mechanism is considered as a polymerization process due to the fast velocity involved [28], and two phases can be identified: hydrogen is released first, which activates the aromatic molecules, followed by the addition of acetylene, which promotes molecular growth and cyclization of $P A H$ [29].

Experimental studies show that the transition between precursor-soot occurs at 500 to $2000 \mathrm{Da}$ [30]. On one hand, due to the high supersaturation of macromolecular precursors, the partial pressure of these precursors acts as a driving force, so that the macromolecules physically condense to yield in a soot liquid phase [31]. On the other 
hand, there is a theory that states that $P A H$ molecules grow until they have a solid transition [32].

In the final stage of soot formation, surface growth is a predominant process which occurs by the addition of mass on the nucleate soot particle surface and leads to an increase in the soot mass, but not in the particle number. During surface growing, active reactants portion of primary soot particle accepts the gas-phase of acetylene hydrocarbons. This mechanism (for surface growing) continues when the primary particles are moved to less active cold areas, where the hydrocarbons concentration is less than the limit of soot inception rate [33].

\section{Experimental facilities}

\subsection{Engine and general instrumentation}

This study was performed in a 2-liter, 4-cylinder, high-speed direct injection diesel engine $(H S D I)$ for passenger car applications. The engine was equipped with exhaust gas recirculation system $(E G R)$ and high-pressure fuel injection using a common-rail injection system. Further detailed specifications of the engine are given in Table 2.

Table 2. Engine's main characteristics.

\begin{tabular}{ll}
\hline Type & 4 -stroke $[-]$ \\
Displacement & $1997\left[\mathrm{~cm}^{3}\right]$ \\
Diameter (D) & $85[\mathrm{~mm}]$ \\
Stroke (S) & $88[\mathrm{~mm}]$ \\
Number of cylinders (z) & $4[-]$ \\
Valves per cylinder & $4[-]$ \\
Compression ratio & $18: 1[-]$ \\
Max. power/speed & $100[\mathrm{~kW}]$ at $4000 \mathrm{rpm}$ \\
Max. torque/speed & $320[\mathrm{Nm}]$ at $1750 \mathrm{rpm}$ \\
\hline
\end{tabular}

Ultra low sulfur diesel $(U L S D)$ fuel was used in all the tests according with European standards and its properties are provided in Table 3.

Table 3. Fuel properties.

\begin{tabular}{ll}
\hline Cetane number & $51.6[-]$ \\
Viscosity at $40^{\circ} \mathrm{C}$ & $2.46\left[\mathrm{~mm}^{2} / \mathrm{s}\right]$ \\
Density at $15^{\circ} \mathrm{C}$ & $0.843[\mathrm{~kg} / \mathrm{l}]$ \\
Lower heating value & $42.055[\mathrm{MJ} / \mathrm{kg}]$ \\
Sulfur content & $6.6[\mathrm{ppm}]$ \\
Water content & $96[\mathrm{ppm}]$ \\
\hline
\end{tabular}


The engine was connected to a dynamometric brake SCHENCK-Dynas3 LI250, which allows instant speed and torque engine control. In order to make possible modifications of engine settings, the Engine Control Unit $(E C U)$ is fully open and the engine settings maps can be recalibrated with the ETAS-INCA software. The test bench was fully equipped with $\mathrm{K}$ thermocouples and mean pressure sensors in the exhaust, cooling, intake and lubrication systems. Fuel consumption was determined by two methods. The first consists of a fuel gravimetric system with AVL-733S Dynamic Fuel Meter. The measurement device consists of a measuring vessel filled with the fuel and suspended on a balance system. Fuel consumption values are obtained by calculating the vessel's weight loss over time. Since the response time of this system may be too long for transient operation, fuel consumption signal provided by the $E C U$ was calibrated in steady state operating conditions, and then used as a second fuel consumption measuring system [34]. For measuring air mass flow rate at intake manifold, Sensyflow-P Sensycon hot-plate anemometer system was used.

\subsection{Experimental setup}

Three different equipment were used in this study for measuring particle and soot emission, as shown in Figure 2.

For particle measurement, TSI-EEPS has been employed in order to allow a fast response in dynamic cycles [35]. TSI-EEPS is capable for measuring particle size distribution with a frequency up to $1 \mathrm{~Hz}$, and provide a measuring range between 5.6 to $560 \mathrm{~nm}$. The methodology used to sampling exhaust aerosol from tailpipe and measure particle size distribution in transient conditions, which is also applicable to steady state conditions, is performed in the laboratory according to Desantes et al. [36] as shown Figure 3. The dilution system used in this study was a DEKATI-FPS 4000 [37], and it accomplished the sample in two stages. A porous tube (PTD) is used as the isothermal primary diluter (A to $\mathrm{B}$ way in Figure 3 ), and then ejector diluter $(E D)$ is used as the secondary diluter (B to $\mathrm{C}$ way in Figure 3 ).

In order to make posible smoke amount quantification present in exhaust gas, a partial-flow opacimeter AVL-439 was used for measuring the opacity of exhaust gas. In this sense, opacimeter is capable to measuring opacity in transient condition [38].

Finally, HORIBA-1230PM, which includes a TSI-DCS device for soot measurement, was used to given a soot emission rate. The system consists of a diffusion charging sensor with a specific dilution device for soot measurement [39].

Despite the continuous development of enhanced exhaust particle analyzers, there are relevant difficulties associated with the emission measurement that have to be taken into account when transient tests are being performed. The main problem is that particle or soot analyzers usually have longer response time than the rest of the engine transducers. Therefore, pollutant emission signals are slightly delayed in comparison with the rest of the engine parameters. Since analyzers measure either particle concentration or soot concentration, exhaust mass flow must be determined to calculate 
the instantaneous mass of pollutants emitted. Therefore, the synchronization between exhaust mass flow and pollutant emission measurement devices becomes critical. The synchronizing method adopted in this study is widely described by Broatch et al.[40].

\subsection{Electrical and optical techniques for particle measurement}

Since the aim of this work is to define the condition measurement for soot emission rate measurement in a device capable for it, and correlate experimental results obtained with different techniques, it is necessary to know the operating principle that each system is using for carried out measurements. Figure 4 shows the operating principle for each measurement systems. TSI-DCS, which is capable to allow soot emission rate, based its operating principle in a diffusor charger. TSI-EEPS equipment, that allows instantaneous particle size distribution, bases its operating principle on the electrical mobility of particles according to their diameters. And finally, AVL-439 opacimeter uses the light extinction technique to determine the percentage of light absorbed by the carbon particles.

- Surface area measurement technique from diffusion charger sensor.

DCS is a device capable for active surface particles measurement in the exhaust gas through a diffussion charger [41]. This active surface area $\left(A_{t o t}\right)$ is proportional to the soot amount present in the exhaust aerosol, as shown equation (2).

$$
A_{t o t}=\frac{1}{\sqrt{\frac{3 k T}{m_{\text {ion }}}}} \frac{d n}{d t}
$$

Where $d n / d t$ is the decrease in the ion concentration due to attack on the suface particles, $k T$ is the Boltzman constant, and $m_{\text {ion }}$ is the electric ion mass.

The measurement principle for the equipment is based on the free ion generation in a high voltage corona discharge (filtered exhaust gas ionization), which attack the active surface of the particles by Brownian forces in axial mixing chamber (Brownian diffusion) [42], as shown the center of Figure 4.A. Excess ions are collected by ion trap using a low voltage electrode, and the charged particles are precipitated on a isolated filter where the current is measured. The measured current is directly the ion union ratio on particle surface, and it is an indicator of the quantity of ions that are absorbed by the particle surface, as shown equation (3) .

$$
\frac{d n}{d t}=\frac{I_{c}}{e_{c}}=-K N_{p o l .} n
$$

Where $n$ is the initial free ions concentration, $K$ is a coefficient which depends of particle concentration, and $N_{\text {pol. }}$ is the polydisperse aerosol concentration. Recombining equations (2) and (3), active surface area is given in terms of the electrometer current. Equation (4) shows how the active surface area is determined. 


$$
A_{t o t}=\frac{1}{e_{c} \sqrt{\frac{3 k T}{m_{i o n}}}} I_{D C S}
$$

- Electrical mobility measurement technique.

Scanning mobility particle size measurements is the extended method for investigating particle size distributions of engines exhaust aerosol during steadystate conditions. In this sense, due to the fact that scan all particle range concentration is needed, acquisition of a particle size distribution takes several minutes. However, the development of segmented differential mobility analyzers has extended allowing detailed analysis to transient engine testing. As stated in 4.2, TSI-EEPS is the system used for PSD measurements in this work. The measurement principle of this device are based on electrical mobility acquired by the particles as a function of its diameter, as shown equation (5).

$$
Z_{p}=\frac{n_{c} e_{c} C}{3 \pi D_{p} \mu}
$$

Where $n_{c}$ is the particle charges number, $C$ is the Cunningham correction factor, $\mu$ is the gas viscosity, and $D_{p}$ is a particle diameter. Therefore, for a polydisperse aerosol, the particles acquire electrical mobility according to their diameter.

Figure 4.B shows the scheme of the measurement principle. Firstly, particle entries in charger zone. In order to solve the problem of multiple charges that particles show, the aerosol charging method has been accomplished through two unipolar needle diffusers. At first glance, a negative needle puts the negative net charge on particles to reduce the number of highly positive charged particles and prevent overcharging in the second needle. Then, positive charger puts a predictable net positive charge on the particles. A series of electrometers downstream of the charging area detect the current in a specific range, capables for detecting a range of associated electrical mobility particle diameter, being able to determine the particle size distribution [15].

- Optical technique for continuous opacimeter.

It is widely known the use of this system for opacity measurement in the exhaust gas. The operation principle of this equipment is based in the Beer-Lambert law, and it can provide online signal of smoke amount present in exhaust gas. Beer-Lambert law relates the current of inlet light (right side in Figure 4.C) in a medium with the outlet current after light absorption by the medium (left side in Figure 4.C). The relationship between the two intensities can be expressed by equation (6).

$$
\frac{I}{I_{0}}=e^{-k L}
$$


Where $k$ term is the gas extinction coefficient, and it is defined as the amount of light extinguished by length unit, which increases as the particle concentration do [44]. Opacity measurement is therefore defined as $N$, which can vary from 0 to 100 and is proportional to a light extinction inside the tube, as defined by equation (7).

$$
\frac{I}{I_{0}}=1-\frac{N}{100}=e^{-k L}
$$

\section{Results and discussion}

\subsection{Measurement method for optimun dilution ratio selection}

In order to validate the soot measurement that HORIBA-1230PM performs through TSI-DCS, particle size distribution and total particle concentration in the exhaust gas during the steady-state operating points have been measured at both the beginning and the end of measurement phase. Figure 5 shows how the measurement process was carried out.

This part of the study has been done because the optimun dilution ratio was not defined for this equipment, so it is necesary to optimize the processes that could infer in the measurement. Figure 6 shows the results of the study for the three steady-state operating points tested.

Plots at the left side of the figure 6 correspond to a particle size distributions of the three steady-state operating point that have been tested, showing particle size distributions taken both at the beginning and end of soot measurement phase. These particle size distributions show variability at each steady-state operating points along the entire measurement phase. Particle size distribution figures show the invariance in the three steady-state operating points. These graphs show that the exhaust gas emission and aerosol composition does not vary during the steady-state points tested. Moreover, plots at the right side of figure 6 show soot measurements allowed by TSI-DCS using the three dilution ratios enables, namely $D R_{8}, D R_{40}$ and $D R_{80}$. Furthermore, accumulation particle mode concentration in the exhaust gas taken at the beginning and end of the measurement phase are presented in the same plot, which is closely linked to the soot composition [16].

It is clearly observed that $D R_{40}$ corresponds to the largest amount of soot measured in all cases. The highest difference between soot measurements at different dilution ratios in the same steady-state point corresponds to the $\mathrm{A}_{(\mathrm{Nuc})}$ operating point. This is due to the fact that particle size distribution in the exhaust gas at this operating point consists mainly in nucleation particle mode concentration. In this particles type $(<30 \mathrm{~nm})$, Brownian diffusion losses have been produced in the charger due to the strong electric field generated in the corona discharge [45], which are depositing in the diffusion charger surface. This is closely linked to the losses in the transfer tube of a given length due to aerosol diffusion and thermophoretic forces at low flow [46]. 
In the case of high accumulation particle mode concentration $\left(\mathrm{C}_{(\mathrm{Ac})}\right)$, another phenomenon associated with lower dilution ratios occurs. A decrease in particle charging efficiency due to the free ions defect for particle attack in the diffusion charger [42] was found. Moreover, focusing on comparison between $D R_{40}$ and $D R_{80}$ measurement do not exist almost difference between them in high accumulation particle mode concentrations (point $\mathrm{B}_{(\mathrm{Bim})}$ and $\mathrm{C}_{(\mathrm{Ac})}$ ). In contrast, at low accumulation particle mode concentration (point $\mathrm{A}_{(\mathrm{Nuc})}$ ) there is a decrease in soot amount measured due to the lower detection limit of the TSI-DCS. High dilution ratios produce a very low particle concentration which cannot be detected by the equipment.

Finally, Figure 7 shows the sensitivity of soot measurement respect to the accumulation particle mode concentration. This variation was calculated according to the equation (8), and allows checking soot measurement variation for each test with different dilution ratios.

$$
\text { Sensitivitymeas. }=\frac{\text { Soot }_{\text {conc. }}}{A c_{\cdot \text { conc. }}}
$$

It is appreciated that the soot measurement taken at the beginning and the end of the measurement phase allows similar variations respect to accumulation particle concentration mode. As shown in Figure $7, D R_{40}$ measurements present a higher sensitivity to soot measurements for the three steady-state operating points, which indicates that this is the optimal dilution ratio for soot measurements with DCS.

\subsection{Transient soot measurement with three simultaneous differents measurement techniques}

Once the optimun dilution ration has been selected, soot data measurement obtained during the assessment of $N E D C$ is presented. It was performed through the three dilution ratios allowed by HORIBA-1230PM to evaluate its influence in the soot measurement on dynamic conditions. Since the aim of this paper is to find empirical correlations between different measurement techniques used, opacity and accumulation mode particle concentration also have been measured at the same time that soot emission rate. Figure 8 shows soot concentration, accumulation particle concentration and opacity measurement along the three $N E D C$ carried out.

As shown in Figure 8.A, soot measurement is affected by the dilution ratio used. During the urban phases $(E C E-15)$ there is not difference between soot measurements with different dilution ratios due to the lower particle concentration at these phases, although it is possible to observe that soot measurement made with $D R_{8}$ is below than other two. When the issue is focused on the EUDC phase, it is clearly visible that $D R_{8}$ soot measurement is different from other two $D R$ measurements. In this case, accumulation mode particle concentration is much higher, so the influence of free ions availables for particle charging is much higher as explained in Section 5.1. 
To ensure that the decrease in soot measurement is not associated to the daily variation, accumulation particle concentration mode and opacity measurements show invariance on the three cycles performed (Figure 8.B and Figure 8.C), obtaining the same accumulation particulate concentrations and opacity values for each cycle.

In order to find the deviation in the measurement of soot mass emitted during whole cycle, the accumulated soot were calculated during the $N E D C$, allowing up to $21.9 \%$ less with $D R_{8}$ than the soot mass measured with $D R_{40}$, which was established as optimum for soot measurement. Figure 9 shows the accumulated soot throughout the $N E D C$ and the difference found when the $D R_{8}, D R_{40}$ and $D R_{80}$ were compared.

\subsection{Proposed correlations for estimation of soot mass rate}

As shown in the previous section, soot concentration, opacity, and accumulation mode particle concentration are closely linked. Figure 10 shows soot concentration, opacity and accumulation particle mode concentration throughout the $E U D C$ phase, and it is clearly visible the correspondence with different measurement techniques. In this phase of NEDC, the increase in accumulation particle mode concentration of exhaust aerosol composition is relevant. Selected data for correlations between different techniques have been chosen from the start of EUDC phase (Idle-0\%load) until the instant before the deceleration ramp $\left(2150 \mathrm{~min}^{-1}-53 \%\right.$ load $)$.

Figure 11 shows over 4000 sample points taken into account during this EUDC phase for analysis and correlation between different techniques. As shown in section 5.1, dilution ratio to be taken into account in the soot measurement are optimized, and $D R_{40}$ has been employed with TSI-DCS for soot measurement.

Figure 12.A1 and figure 12.B1 show the two correlations obtained from the opacity to soot measurement, and between the accumulation mode particle concentration to soot measurement. In order to correlate the different techniques and validate the regressions that has been obtained, it has been made a statistical data analysis, where it is found correspondence with an $R^{2}=89.8 \%$ between opacity and soot measurement (in the range from $0 \%$ to $40 \%$ ); and an $R^{2}=93.7 \%$ for the accumulation particle mode concentration and soot measurement (in the accumulation particle concentration range from 0 to $2 * 10^{14} \# / \mathrm{m}^{3}$ ). Both correlations have been evaluated for a $95 \%$ confidence interval [47]. Furthermore, Figure 12.A2 and Figure 12.B2 show the data that have been measured versus values that have been obtained with correlations, ckecking that the adjustment corresponds to the measured values.

In the opacity case, the adjusted correlation corresponds to equation (9):

$$
\begin{aligned}
\text { Soot }_{\text {conc. }} & =7.148438+5.72431[N]- \\
& -0.0995499[N]^{2}
\end{aligned}
$$

In the case of accumulation particle mode concentration, the correlation found is as follows equation (10): 


$$
\begin{aligned}
\text { Soot }_{\text {conc. }} & =3.53435+2.65092 E^{-13}\left[\text { Ac. }_{\text {conc. }}\right]+ \\
& +8.07561 E^{-28}[\text { Ac.conc. }]^{2}
\end{aligned}
$$

\subsection{Soot emission rate correlations validation}

In order to validate the proposed correlations, entire $N E D C$ cycle has been carried out to ensure the correlations response versus dynamic cycles. Instantaneous concentrations and accumulated results are shown in Figure 13.

Figure 13.A shows instantaneous soot concentration throughout the cycle obtained by HORIBA-1230PM throught TSI-DCS direct measurement, and the instantaneous soot concentration obtained through the proposed correlations. Furthermore, figure 13.B shows the total soot mass emitted throughout the cycle using correlations and direct measurement. Table 4 shows the variation of both correlations compared to direct soot measurement, not getting to $4 \%$ deviation.

Table 4. Variations for proposed correlations.

\begin{tabular}{lc}
\hline Correlation & Variation [\%] \\
\hline Opacity correlation & 3.49 \\
Accumulation part. correlation & -1.93 \\
\hline
\end{tabular}

At first glance, opacity correlation overestimates soot concentration during the whole cycle due to $\mathrm{NO}_{2}$ interference during the opacity measurement. Since this compound has optical properties for light absorption [48], it can be decrease light intensity reaching the optical detector, thereby increasing the opacity measurement.

Jones states that opacimeters can detect between $0.00016 \mathrm{~m}^{-1}$ and $0.00024 \mathrm{~m}^{-1}$ of light extinction coefficient per $\mathrm{NO}_{2} \mathrm{ppm}$ [49], so that $30 \mathrm{ppm}$ typical concentration of $\mathrm{NO}_{2}$ at idle operating point has a $0.006 \mathrm{~m}^{-1}$ light absorption coefficient, which corresponds to an increase of $2.2 \%$ in the opacity. Note also that the opacimeter presents quite dispersion below $2 \%$ opacity $\left(\mathrm{k}=0.001 \mathrm{~m}^{-1}\right)$, which is the measurement resolution of the equipment [50].

Instead, the particle correlation presents a fairly accurate adjustment since this model takes into account the particle morphology (accumulation particle mode) of the exhaust gas aerosol, so that deviations obtained with the model are almost negligible.

\section{Summary and Conclusion}

Nowadays, the necessity to estimate soot amount emitted by current engines during transient conditions are increasing importance. Due to this fact, soot measurement systems for transient conditions are being used. In this sense, it is necessary to define measurement conditions for the use of this analyzer and check what kinds of influence 
factors affect the soot measurement in order to perform test with the least variability possible.

On this basis, a comprehensive experimental analysis of how dilution ratio affects soot measurement was performed in steady-state operating conditions. A sensitivity analysis shows the variability on soot measurement when three different dilution ratios were used, allowing a recommendation for the dilution ratio applied. Moreover, dynamic tests through NEDC confirm that the selected dilution ratio allows less deviation in the soot measurements.

Furthermore, there were two new correlations between different measurement techniques to estimate an instantaneous soot mass concentration from a light-duty diesel engine through transient conditions measuring opacity or accumulation particle mode concentration present in the exhaust gas.

Based on the analysis of the results, the following conclusions were highlighted.

- The dilution ratio employed significantly affects to soot measurement due to the particle charging process inside the analyzer. The optimun dilution ratio value found in this study was 40 .

- TSI-DCS has been validated as a system capable for determining the soot concentration in transient operating conditions, showing a high speed in the response of the analyzer.

- Correlations for estimate soot concentration through different measurement techniques have a fit with a $R^{2}=93.7 \%$ for accumulation particle mode correlation and a $R^{2}=89.8 \%$ for opacity correlation, and a deviation of $3.49 \%$ and $-1.93 \%$ respect to TSI-DCS direct soot measurement respectively.

\section{Acknowledgments}

The equipment used in this work has been partially supported by FEDER project funds "Dotación de infraestructuras científico técnicas para el Centro Integral de Mejora Energética y Medioambiental de Sistemas de Transporte (CiMeT), (FEDERICTS-2012-06)", framed in the operational program of unique scientific and technical infrastructure of the Ministry of Science and Innovation of Spain.

\section{References}

[1] K. Siegmann and H. C. Siegman. Fast and reliable "in situ" evaluation of particles and their surface with special reference to diesel exhaust. SAE Technical Paper, 2000-01-1995.

[2] APHEIS (Air Pollution and Health: A European Information System) Third Year Report. Institut de Veille Sanitaire, Sant-Maurice. European Comission, 2004.

[3] C. I. Davidson, R. F. Phalen, and P. A. Solomon. Airbone particulate matter and human health: a review. Aerosol Sci. Technol., 39(1):62-78, 2005.

[4] C. A. Pope, D. V. Bates, and M. E. Raizenne. Health effects of particulate air pollutions: time for reassessment?. Environ. Health Perspect., 103(5):472-480, 1995. 
[5] Council Directive 1999/30/EC of 22 April 1999 relating to limit values for sulphur dioxide, nitrogen dioxide and oxides of nitrogen, particulate matter and lead in ambient air.

[6] B. Giechaskiel, P. Dilara, E. Sandbach, and J. Andersson. Particle measurement programme (PMP) light-duty inter-laboratory exercise: comparison of different particle number measurement systems. Measurement Science and Technology, 19:095401, 2008. doi:10.1088/0957-0233/19/9/095401.

[7] P. Kihong, D. B. Kittelson, and McMurry P. H. Structural properties of diesel exhaust particles measured by transmission electron microscopy (TEM): Relationships to particle mass and mobility. Aerosol Science and Technology, 38(9):881-889, 2004.

[8] L. Chin-Hsiang, L. Whei-May, and L. Jiun-Jian. Morphological and semi-quantitative characteristics of diesel soot agglomerates emitted from commercial vehicles and a dynamometer. Journal of Environmental Sciences, 21(4):452-457, 2009.

[9] M. M. Maricq. Chemical characterization of particulate emission from diesel engines: A review. Journal of Aerosol Science, 38(11):1079-1118, 2007.

[10] 2008/692/EC, Implementing and amending regulation (EC) n. $715 / 2007$ of the european parliament and of the council on type-approval of motor vehicles with respect to emissions from light passenger and commercial vehicles (EURO 5 and EURO 6) and on access to vehicle repair and maintenance information.

[11] G. Buonanno, M. Dell'Isola, L. Stabile, and A. Viola. Critical aspects of the uncertainty budget in the gravimetric PM measurements. Measurement, 44(1):139-147, 2011.

[12] J. P. R. Symonds, K. StJ. Reavell, J. S. Olfert, B. W. Campbell, and S. L. Swift. Diesel soot mass calculation in real-time with a differential mobility spectrometer. Aerosol Science, 38(1):52-68, 2007.

[13] M. D. Luque de Castro and F. Priego-Capote. Soxhlet extraction: Past and present panacea. Journal of Chromatography, 1217(16):2383-2389, 2010.

[14] S. C. Wang and R. C. Flagan. Scanning electrical mobility spectrometer. Aerosol Science and Technology, 13(2):230-240, 1990.

[15] T. Johnson, R. Caldow, A. Pocher, A. Mirme, and D. \& Kittelson. An engine exhaust particle sizer spectrometer for transient emission particle measurements. SAE Technical Paper, 2004-01-1341.

[16] K. O. Lee, R. Cole, and R. Sekar. Detailed characterization of morphology and dimensions of diesel particulates via thermophoretic sampling. SAE Technical Paper, 2002-01-3572.

[17] V. R. Christian, F. Knopf, A. Jaschek, and W. Schindler. Eine neue meßmethodik der BoschZahl mit erhöhter Empfindlichkeit. MTZ Motortech. Z., 54:16-22, 1993.

[18] A. Y. Snegirev, G. M. Makhviladze, and J. P. Roberts. The effect of particle coagulation and fractal structure on the optical properties and detection of smoke. Fire Safety Journal, 36(1):73-95, 2001.

[19] Z. Q. Zhou, T. U. Ahmed, and M. Y. Choi. Measurement of dimensionless soot extinction constant using a gravimetric sampling technique. Exp. Therm. Sci., 18:27-32, 1998.

[20] J. Arrègle, V. Bermúdez, J. R. Serrano, and E. Fuentes. Procedure for engine transient cycle emissions testing in real time. Exp. Therm. Sci., 30(5):485-96, 2006.

[21] AVL 415S. Technical note. Smoke-meter, the new correlation curve. www.avl.com.

[22] V. Bermúdez, J. M. Luján, J. R. Serrano, and B. Pla. Transient particle emission measurement with optical techniques. Measurement Science and Technology, 19:065404, 2008. doi:10.1088/0957-0233/19/6/065404.

[23] M. Lapuerta, O. Armas, and A. Gómez. Diesel particle size distribution estimation from digital image analysis. Aerosol Science and Technology, 37(4):369-381, 2003.

[24] A. Y. Watson and P. A. Valberg. Carbon black and soot: two different substances. AIHAJ, 62(2):218-228, 2001.

[25] D. R. Tree and K. I. Svensson. Soot processes in compression ignition engines. Progress in Energy and Combustion Science, 33(3):272-309, 2007.

[26] O. I. Smith. Fundamentals of soot formation in flames with application to diesel engine particulate 
emission. Progress in Energy and Combustion Science, 7(4):275-91, 1981.

[27] B. S. Haynes and H. Gg. Wagner. Soot formation. Progress in Energy and Combustion Science, $7(4): 229-273,1981$.

[28] F. Mauss, B. Trilken, H. Breitbach, and N. Peters. Soot formation in partially premixed diffusion flames at atmospheric pressure. Springer Series in Chemical Physics, 59:325-349, 1994.

[29] M. Frenklach and H. Wang. Detailed mechanism and modeling of soot particle formation. Springer Series in Chemical Physics, 59:165-192, 1994.

[30] H. Bockhorn and T. Schäfer. Growth of soot particles in premixed flames by surfaces reactions. Springer Series in Chemical Physics, 59:253-274, 1994.

[31] E. Ranzi, A. Sogaro, P. Gaffuri, G. Pennati, and C. K. Westbrook. New comprehensive reaction mechanism for combustion of hydrocarbon fuels. Combustion flame, 99(2):201-11, 1994.

[32] C. A. Amann and D. C. Siegla. Diesel Particulates-What They Are and Why. Aerosol Science and Technology, 1(1):73-101, 1981.

[33] I. M. Kennedy. Models of soot formation and oxidation. Progress in Energy and Combustion Science, 23(2):95-132, 1997.

[34] J. Galindo, V. Bermúdez, J. R. Serrano, and J. J. López. Cycle to cycle diesel combustion characterization during engine transient operation. SAE Technical Paper, 2001-01-3262.

[35] TSI. Model 3090. Engine Exhaust Particle Sizer spectrometer. Operation and service manual.

[36] J. M. Desantes, V. Bermúdez, S. Molina, and W. G. Linares. Methodology for measuring exhaust aerosol size distributions using an engine test under transient operating conditions. Measurement Science and Technology, 22:115101, 2011. doi:10.1088/0957-0233/22/11/115101.

[37] Dekatiß fine smart particle sampler FPS-4000. Operation and service manual.

[38] AVL 439 Opacimeter. AVL LIST GMBH. Graz. User manual. Operation and service manual.

[39] R. M. Montajir, T. Kusaka, Y. Bamba, and M. Adachi. A new concept for real-time measurement of particulate matter (Soot and SOF). SAE Technical Paper, 2005-01-3605.

[40] A. Broatch, J. M. Luján, J. R. Serrano, and B. Pla. Pollutants instantaneous measurement and data analysis of engine in the loop tests. THIESEL. Conf. Thermo and Fluid Dynamic Processes in Diesel Engines (Valencia, September 2006).

[41] M. Kasper. The number concentration of non-volatile particles - design study for an instrument according to the PMP recommendations. SAE Technical Paper, 2004-01-0960.

[42] P. A. Baron and K. Willeke. Aerosol measurement: Principles, techniques, and applications. Wiley-Interscience, 2001.

[43] TSI. Model DCS-100. Diffusion charging sensor. Operation and service manual.

[44] D. M. Roessler. Diesel particle mass concentration by optical techniques. Applied optics, 21(22):4077-86, 1982.

[45] D. Park, M. An, and J. Hwang. Development and performance test of a unipolar diffusion charger for real-time measurements of submicron aerosol particles having a log-normal size distribution. Journal of Aerosol Science, 38(12):1240-1245, 2007.

[46] W. C. Hinds. Aerosol technology: Properties, behavior, and measurement of airbone particles. Wiley-Interscience, 1999.

[47] Statgraphics@ Centurion XVI. Operation and service manual.

[48] M. Martin and U. Lehmann. Comparison study of particle measurement systems for future approval application. Swiss contribution to GRPE particle measurement programe. (GRPEPMP CH5). Research report 202779. Laboratory for internal combustion engines and furnaces, 2003.

[49] M. Jones. Advanced opacimeters: their potential role in future emission testing legislation for diesel vehicles. Zurich. 2000.

[50] ISO 11614. Reciprocating internal combustion compression-ignition engines apparatus for measurement of the opacity and for determination of the light absorption coefficient of exhaust gas. 


\section{List of Tables}

- Table 1.- Steady state operating points for validation the soot measurement.

- Table 2.- Engine's main characteristics.

- Table 3.- Fuel properties.

- Table 4.- Variations for proposed correlations.

\section{List of Figures}

- Figure 1.- Soot particle formation. Diagram of the different formation phases.

- Figure 2.- Experimental set-up for the evaluation of particle measurement by different measurement techniques.

- Figure 3.- Particle evolution at dilution system. Theoretical phase diagram used in the metodology for measuring particle distribution size.

- Figure 4.- Equipment measuring principle. A) Diffusion charging sensor [43]. B) Engine exhaust particle sizer [35]. C) Opacimeter [38].

- Figure 5.- Methodology applied for soot measurement evaluation under different dilution ratios at each steady-state operating point performed.

- Figure 6.- Soot measurement validation by diffusion charger sensor. A.1) PSD at $\mathrm{A}_{(\mathrm{Nuc})}$ steady-state operating point. A.2) Variation in soot emission rate and accumulation particle concentration measurement with different dilution ratio during $\mathrm{A}_{(\mathrm{Nuc})}$ steady-state operating point. B.1) PSD at $\mathrm{B}_{(\mathrm{Bim})}$ steady-state operating point. B.2) Variation in soot emission rate and accumulation particle concentration measurement with different dilution ratio during $\mathrm{B}_{(\mathrm{Bim})}$ steady-state operating point. C.1) PSD at $\mathrm{C}_{(\mathrm{Ac})}$ steady-state operating point. C.2) Variation in soot emission rate and accumulation particle concentration measurement with different dilution ratio during $\mathrm{C}_{(\mathrm{Ac})}$ steady-state operating point.

- Figure 7.- Sensitivity of soot measurement as function of dilution ratio used.

- Figure 8.- Variation in dynamic particle emission with different measurement techniques during a NEDC at the three different tests evaluated. A) Soot measurement evolution. B) Accumulation particle mode evolution. C) Opacity measurement evolution.

- Figure 9.- Accumulated soot measurement during NEDC with three dilution ratios evaluated.

- Figure 10.- Emission level in soot, opacity, and particle concentration measurement in EUDC phase.

- Figure 11.- NEDC points used for relate different measurements techniques.

- Figure 12.- Proposed correlations for different measurements techniques. A.1) Soot-opacity correlation. A.2) Predicted vs. observed points after correlation 
application. B.1) Soot-Accumulation particle concentration correlation. Predicted vs. observed points after correlation application.

- Figure 13.- Evaluation of porposed correlation during a NEDC.

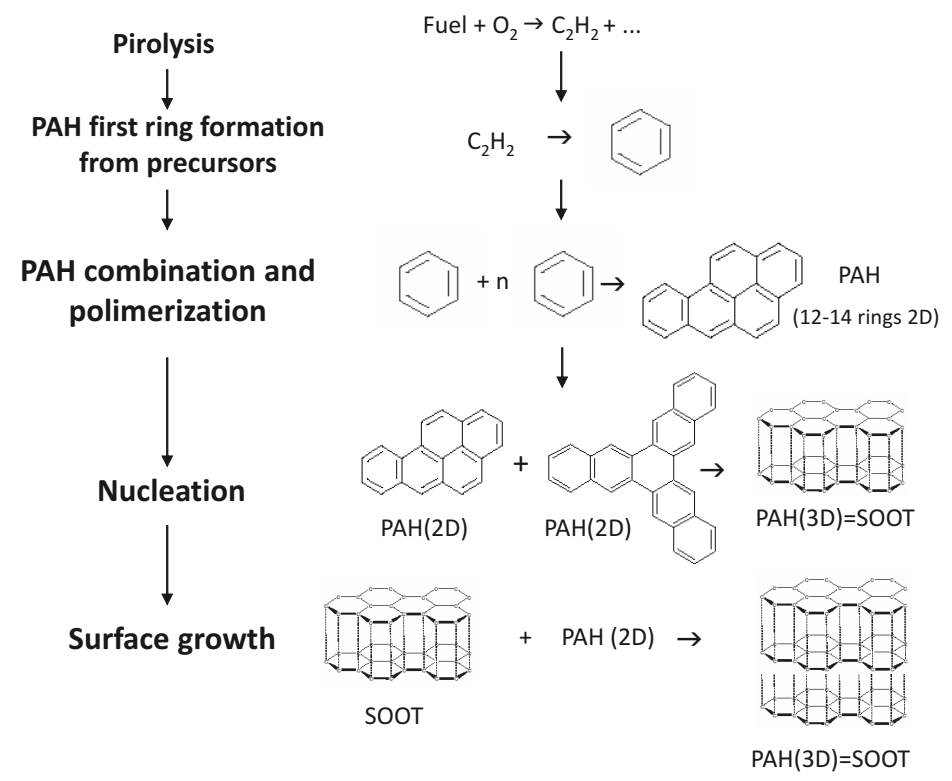

Figure 1. Soot particle formation. Diagram of the different formation phases.

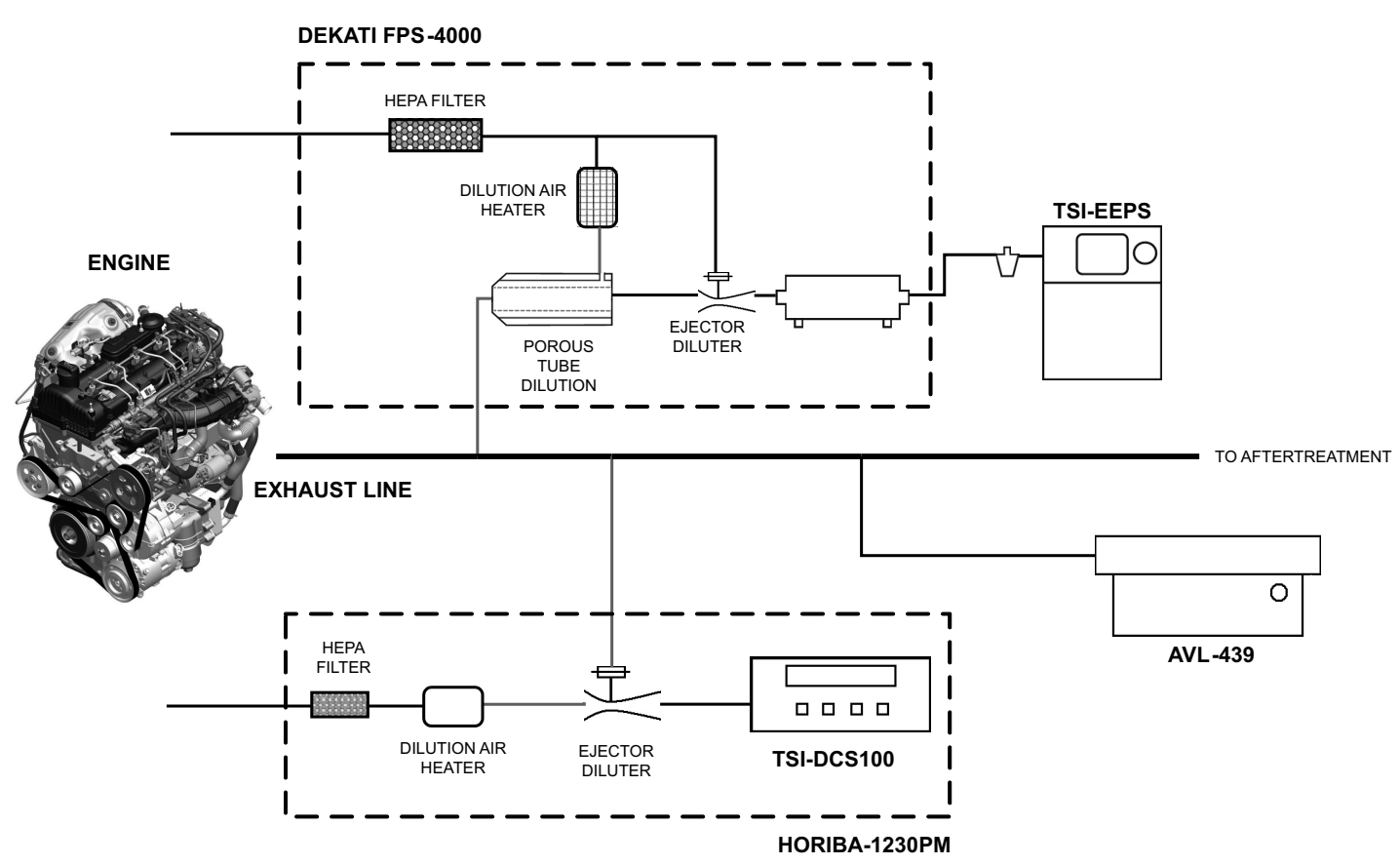

Figure 2. Experimental set-up for the evaluation of particle measurement by different measurement techniques. 


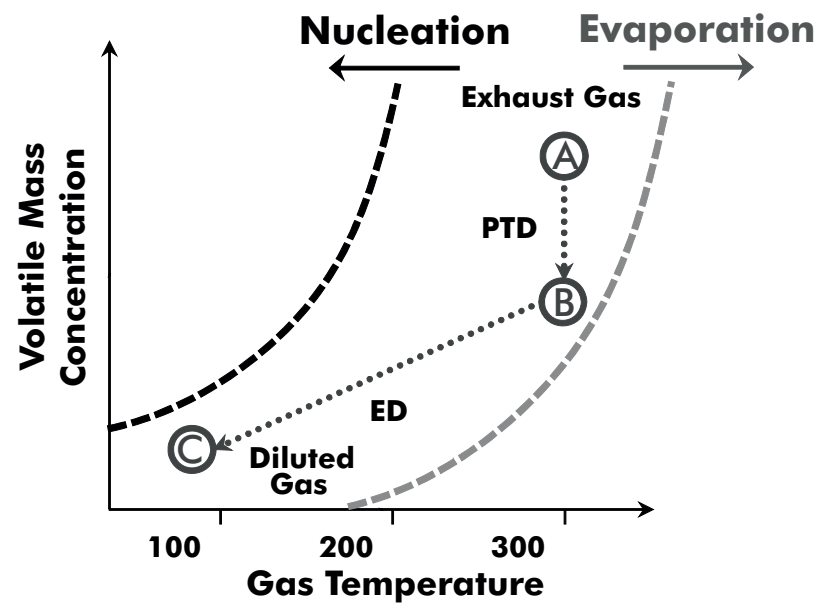

Figure 3. Particle evolution at dilution system. Theoretical phase diagram used in the metodology for measuring particle distribution size [36].
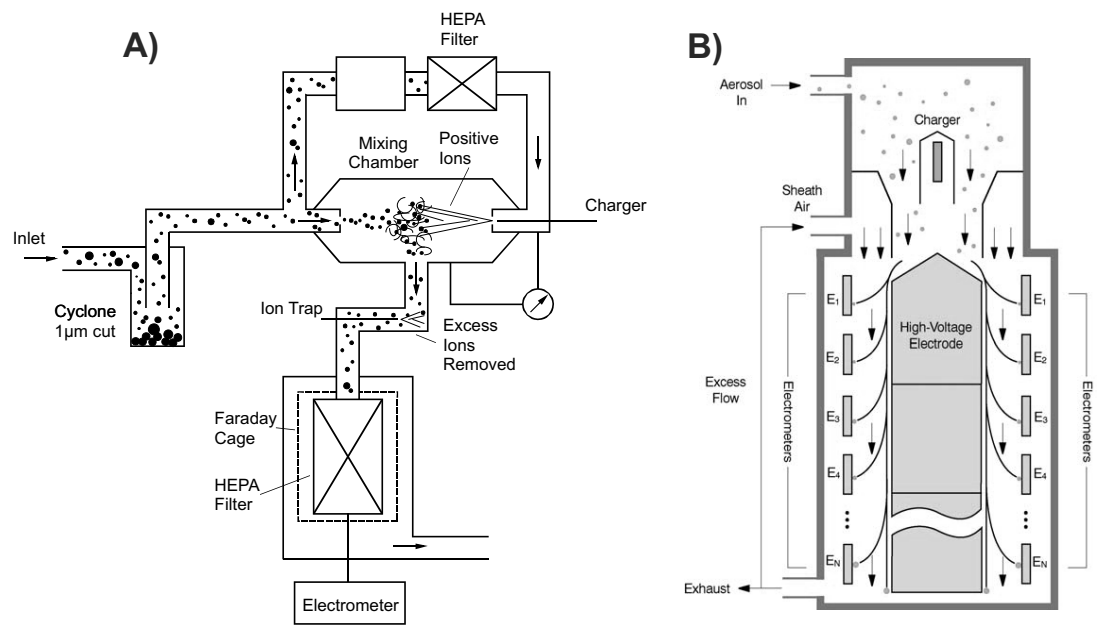

C)

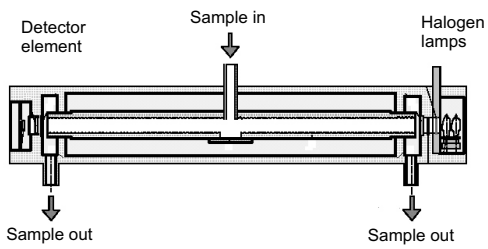

Figure 4. Equipment measuring principle. A) Diffusion charging sensor [43]. B) Engine exhaust particle sizer [35]. C) Opacimeter [38]. 


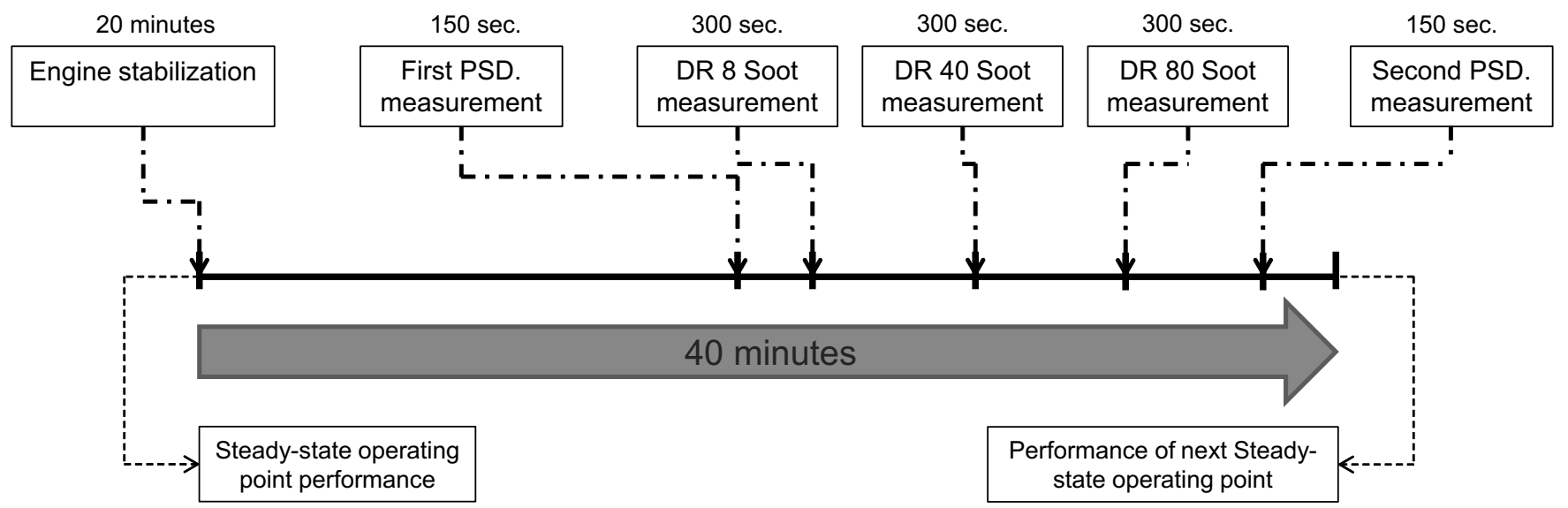

Figure 5. Methodology applied for soot measurement evaluation under different dilution ratios at each steady-state operating point performed. 
- Particle size distribution_Test-1 Acumulation particle concentration

- - Particle size distribution_Test-2 Soot measurement

A.1)

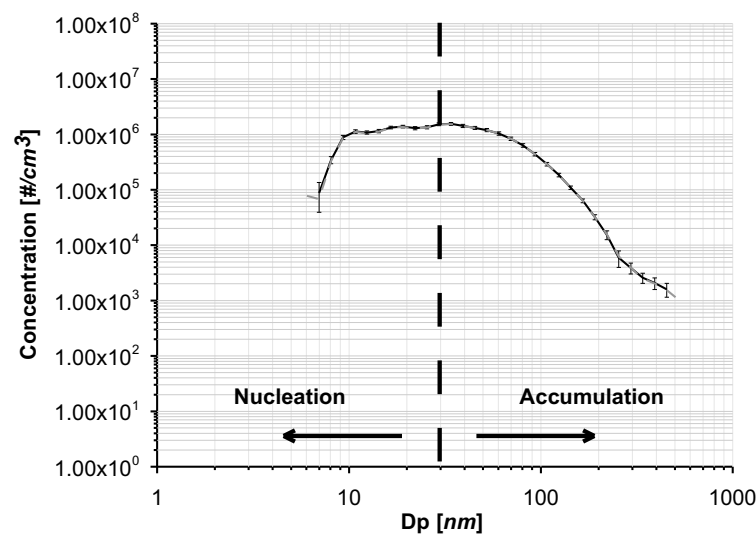

B.1)

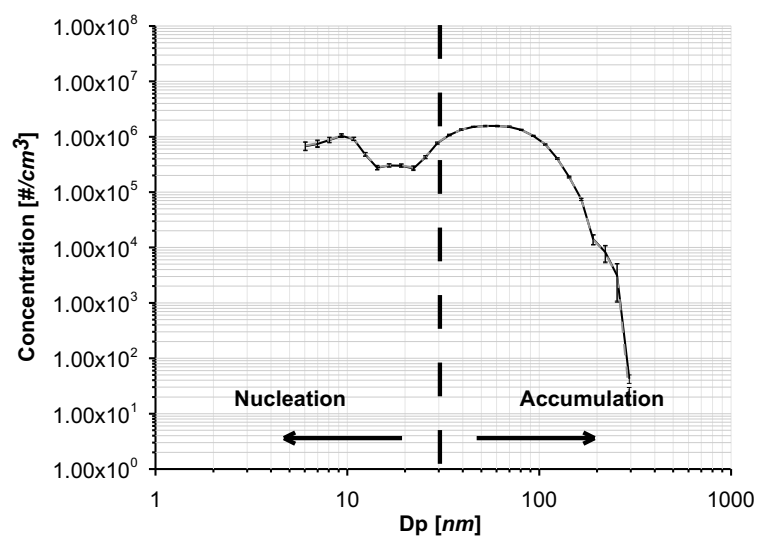

C.1)

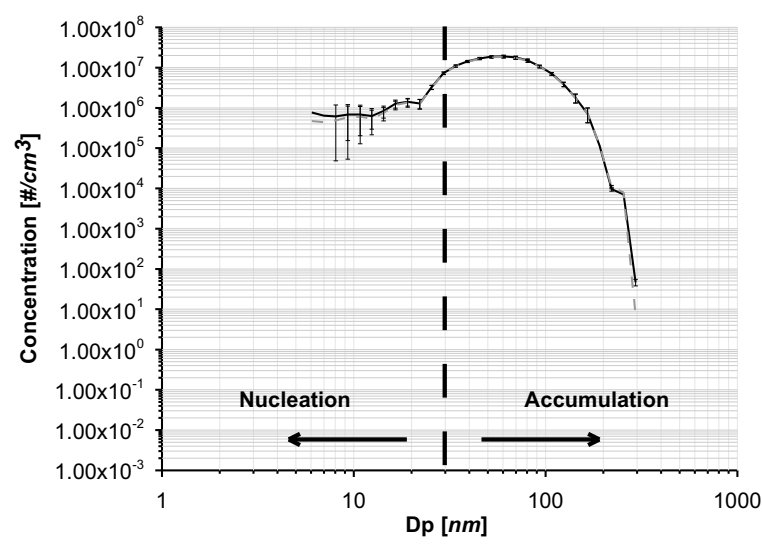

A.2)

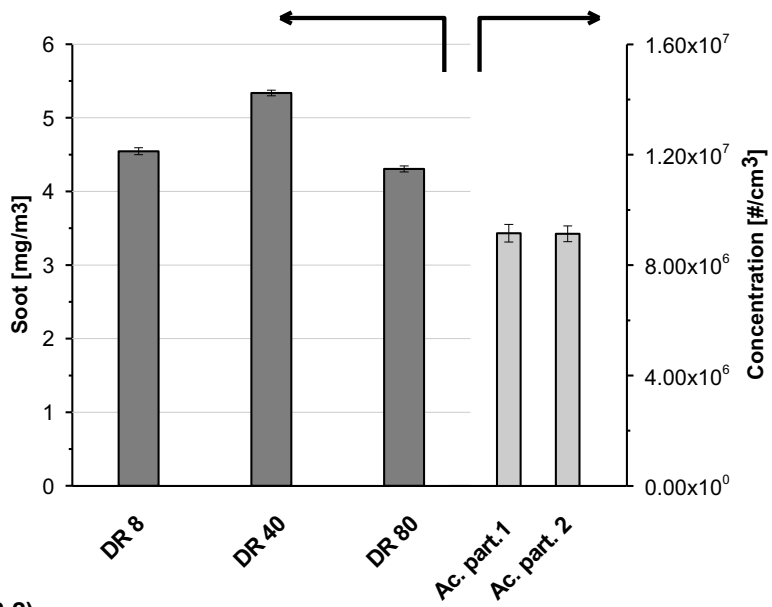

B.2)

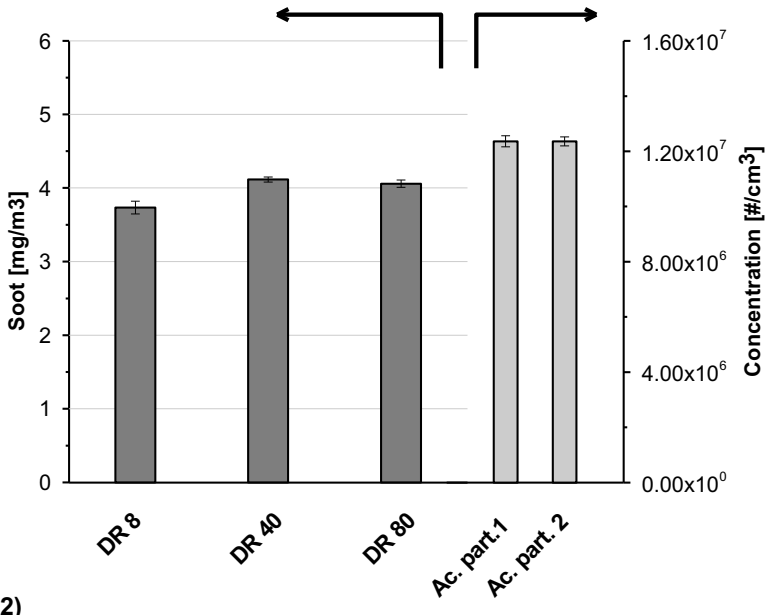

C.2)

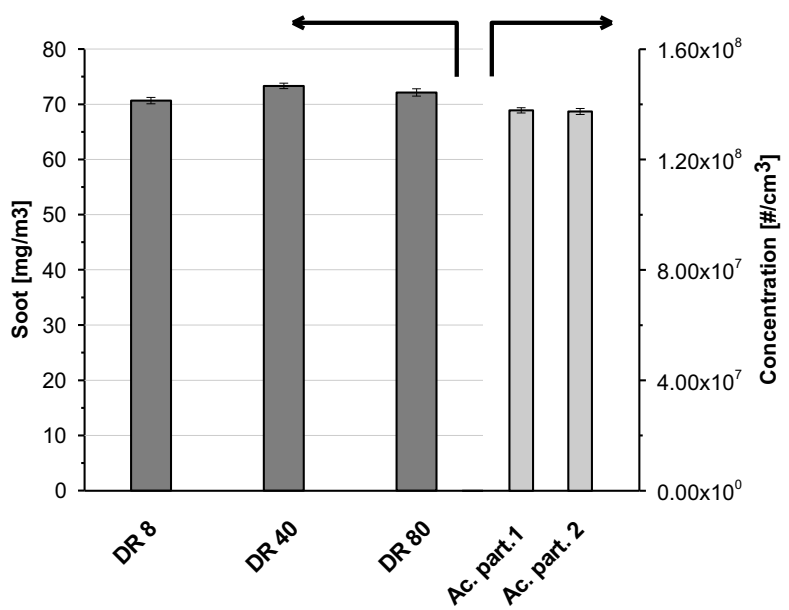

Figure 6. Soot measurement validation by diffusion charger sensor. A.1) PSD at $\mathrm{A}_{(\mathrm{Nuc})}$ steady-state operating point. A.2) Variation in soot emission rate and accumulation particle concentration measurement with different dilution ratio during $\mathrm{A}_{(\mathrm{Nuc})}$ steady-state operating point. B.1) PSD at $\mathrm{B}_{(\mathrm{Bim})}$ steady-state operating point. B.2) Variation in soot emission rate and accumulation particle concentration measurement with different dilution ratio during $\mathrm{B}_{(\mathrm{Bim})}$ steady-state operating point. C.1) PSD at $\mathrm{C}_{(\mathrm{Ac})}$ steady-state operating point. C.2) Variation in soot emission rate and accumulation particle concentration measurement with different dilution ratio 


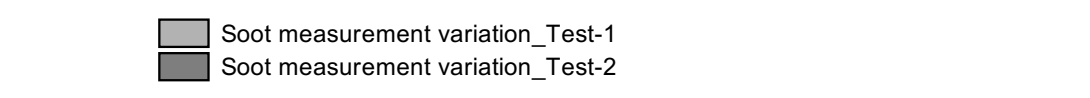

A)

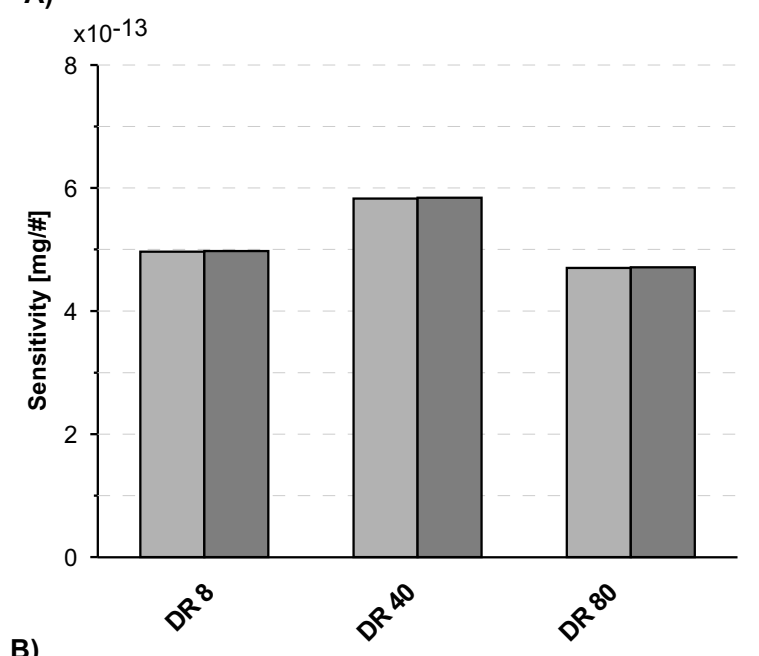

B)

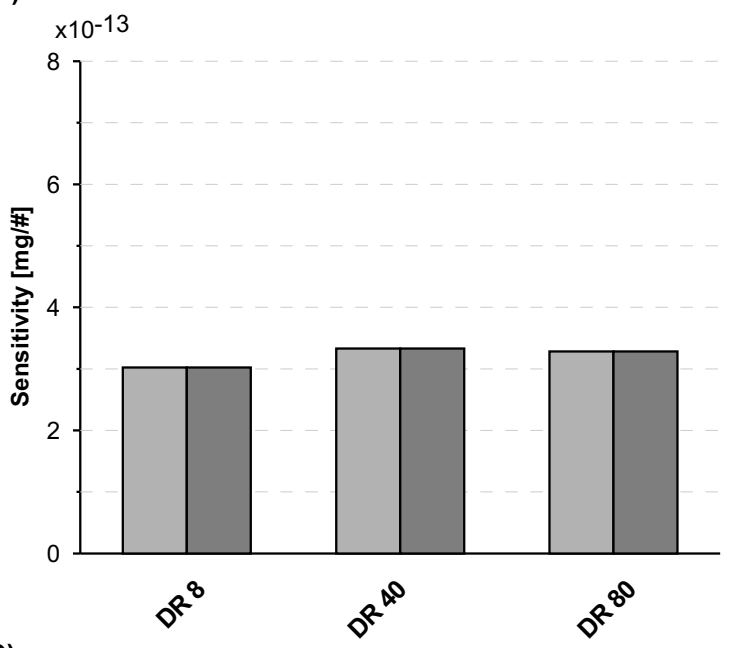

C)

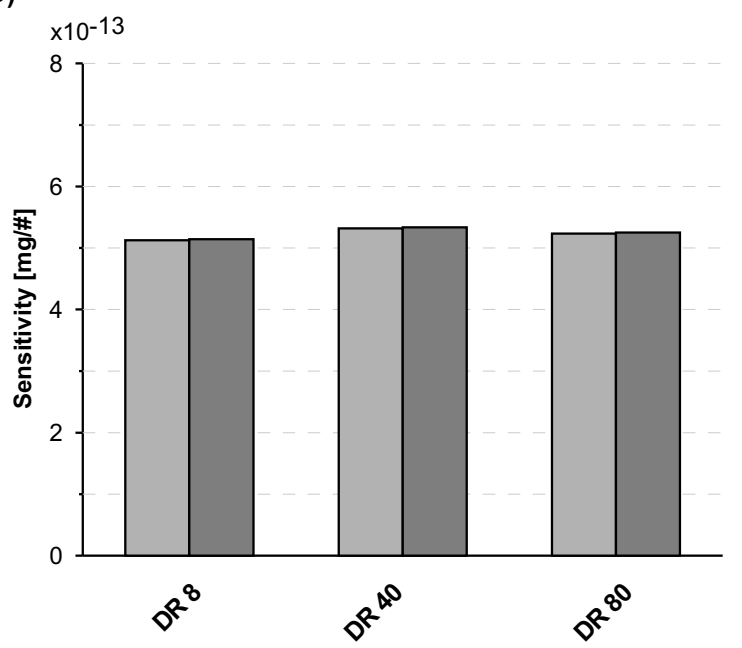

Figure 7. Sensitivity of soot measurement as function of dilution ratio used. 

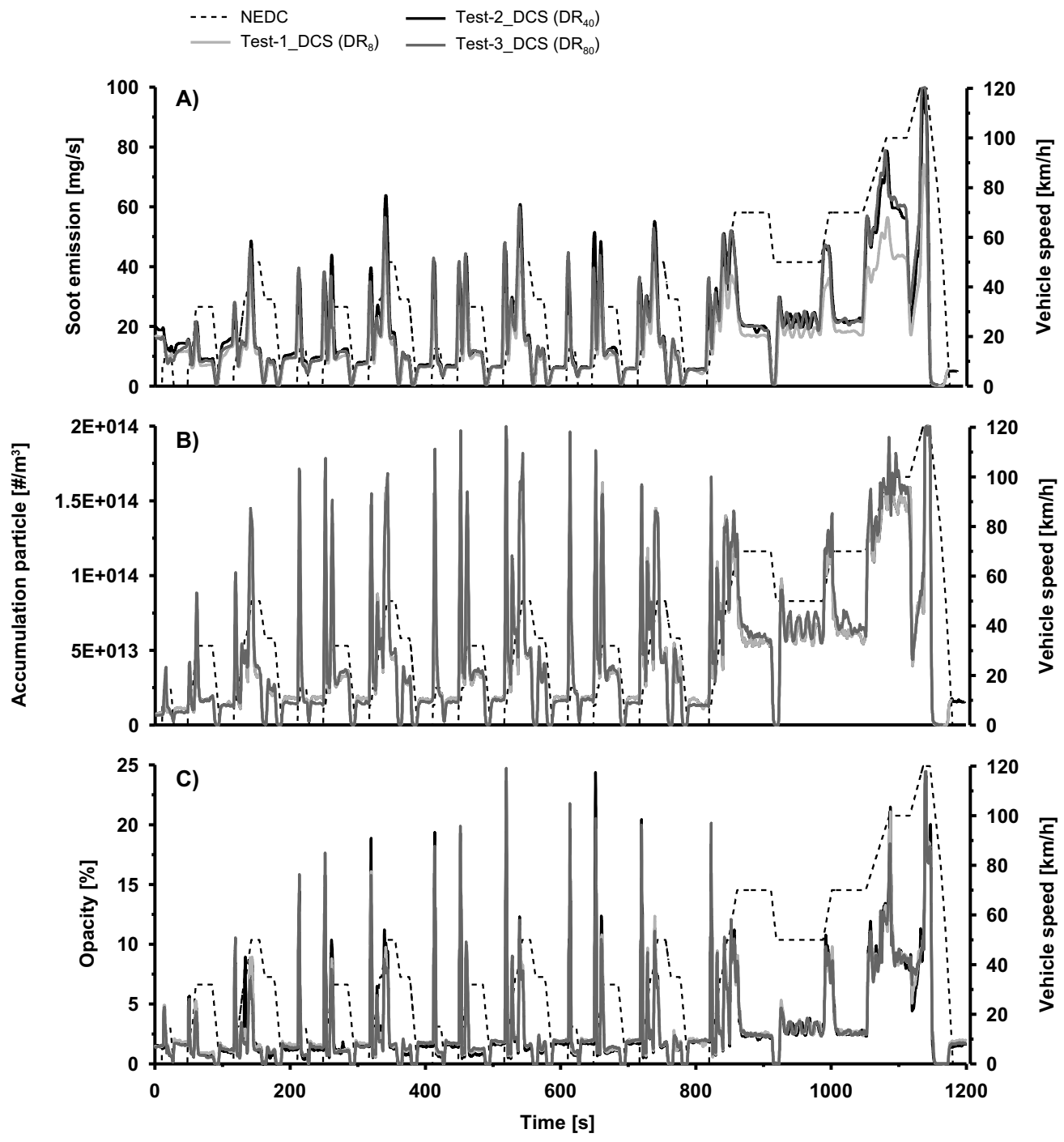

Figure 8. Variation in dynamic particle emission with different measurement techniques during a NEDC at the three different tests evaluated. A) Soot measurement evolution. B) Accumulation particle mode evolution. C) Opacity measurement evolution. 

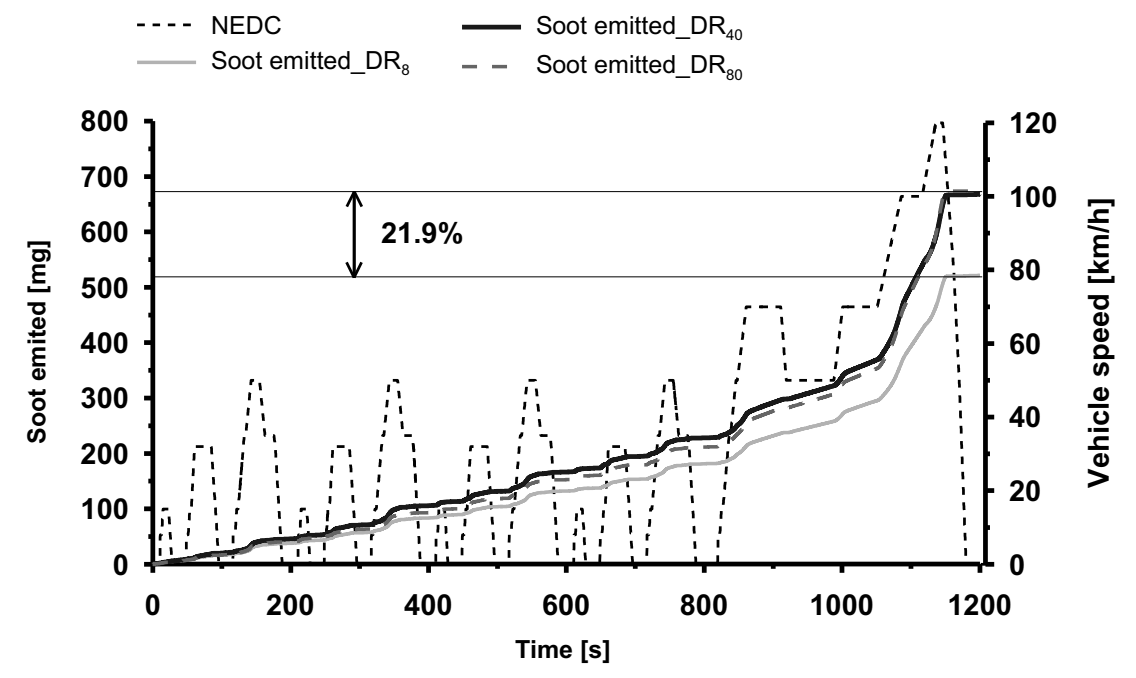

Figure 9. Accumulated soot measurement during NEDC with three dilution ratios evaluated.
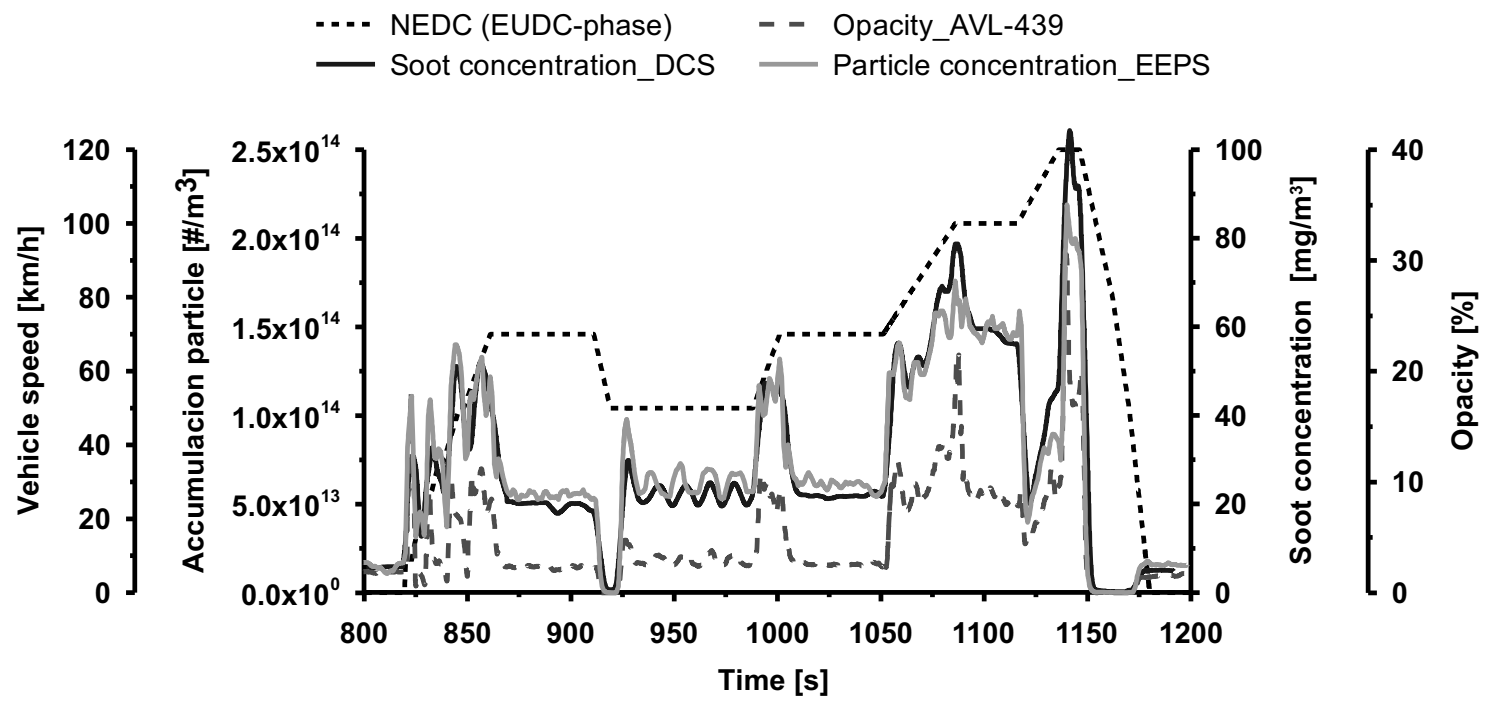

Figure 10. Emission level in soot, opacity, and particle concentration measurement in EUDC phase. 


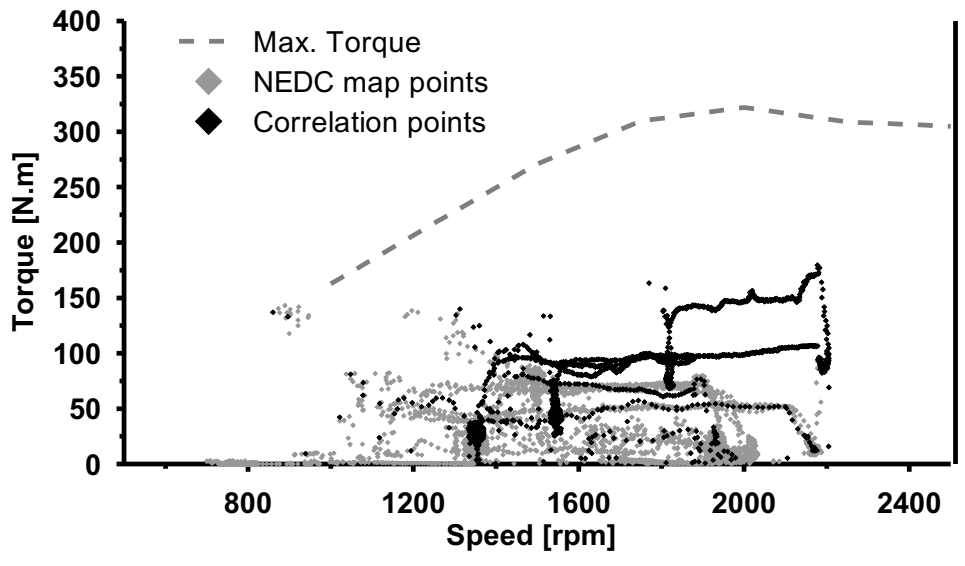

Figure 11. NEDC points used for relate different measurements techniques. 
- Correlated points

A.1)

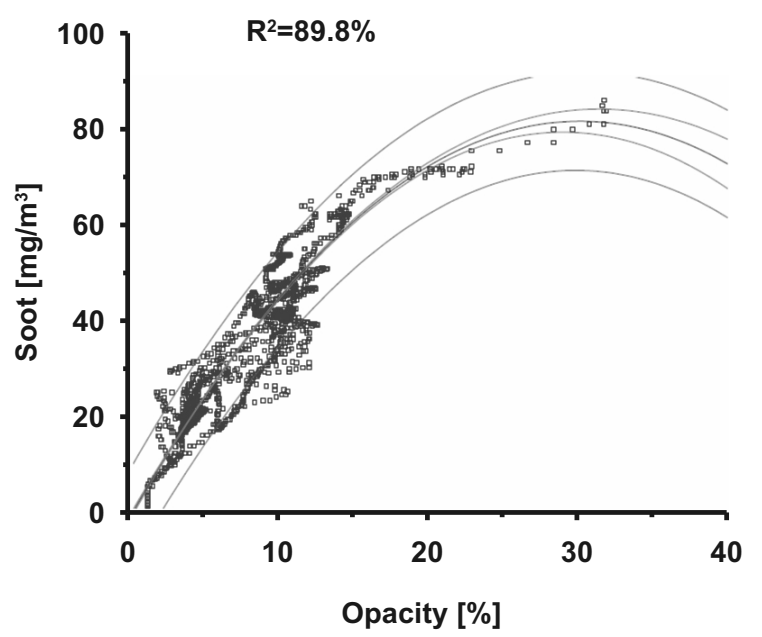

B.1)

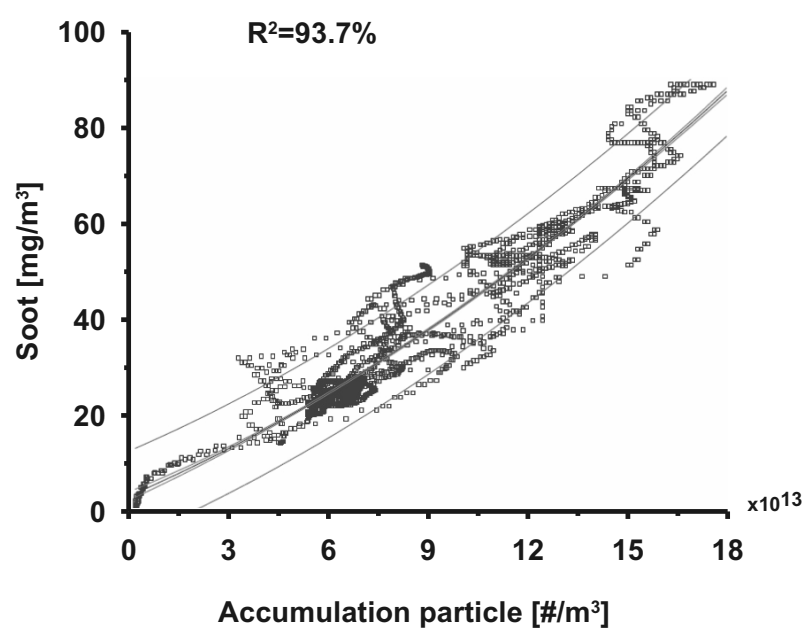

A.2)

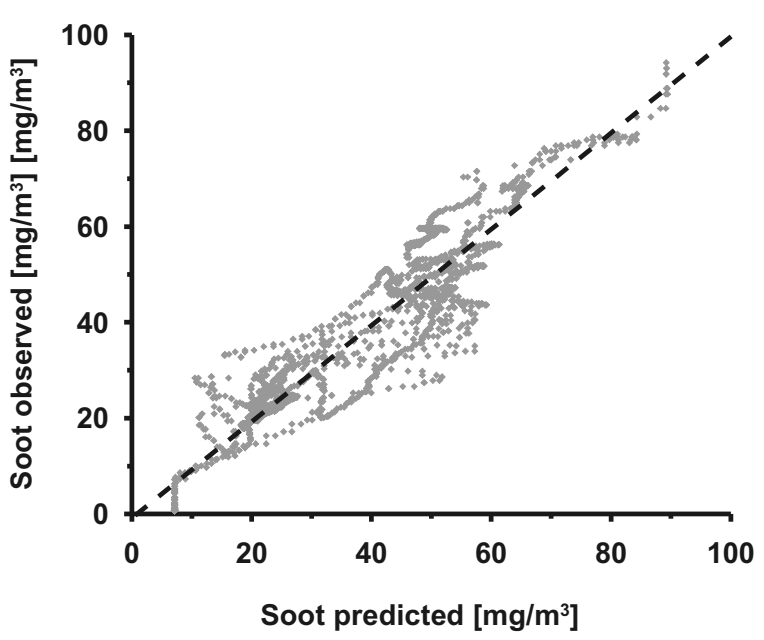

B.2)

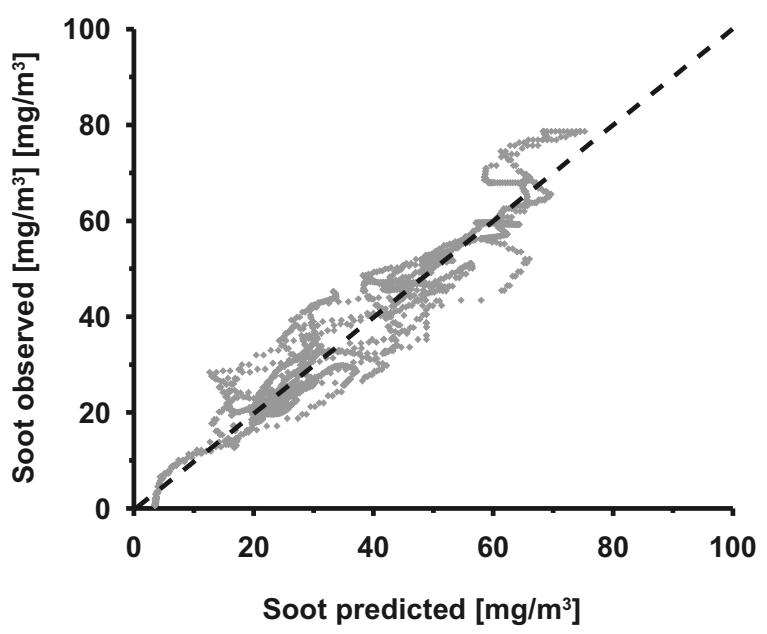

Figure 12. Proposed correlations for different measurements techniques. A.1) Sootopacity correlation. A.2) Predicted vs. observed points after correlation application. B.1) Soot-Accumulation particle concentration correlation. B.2) Predicted vs. observed points after correlation application. 


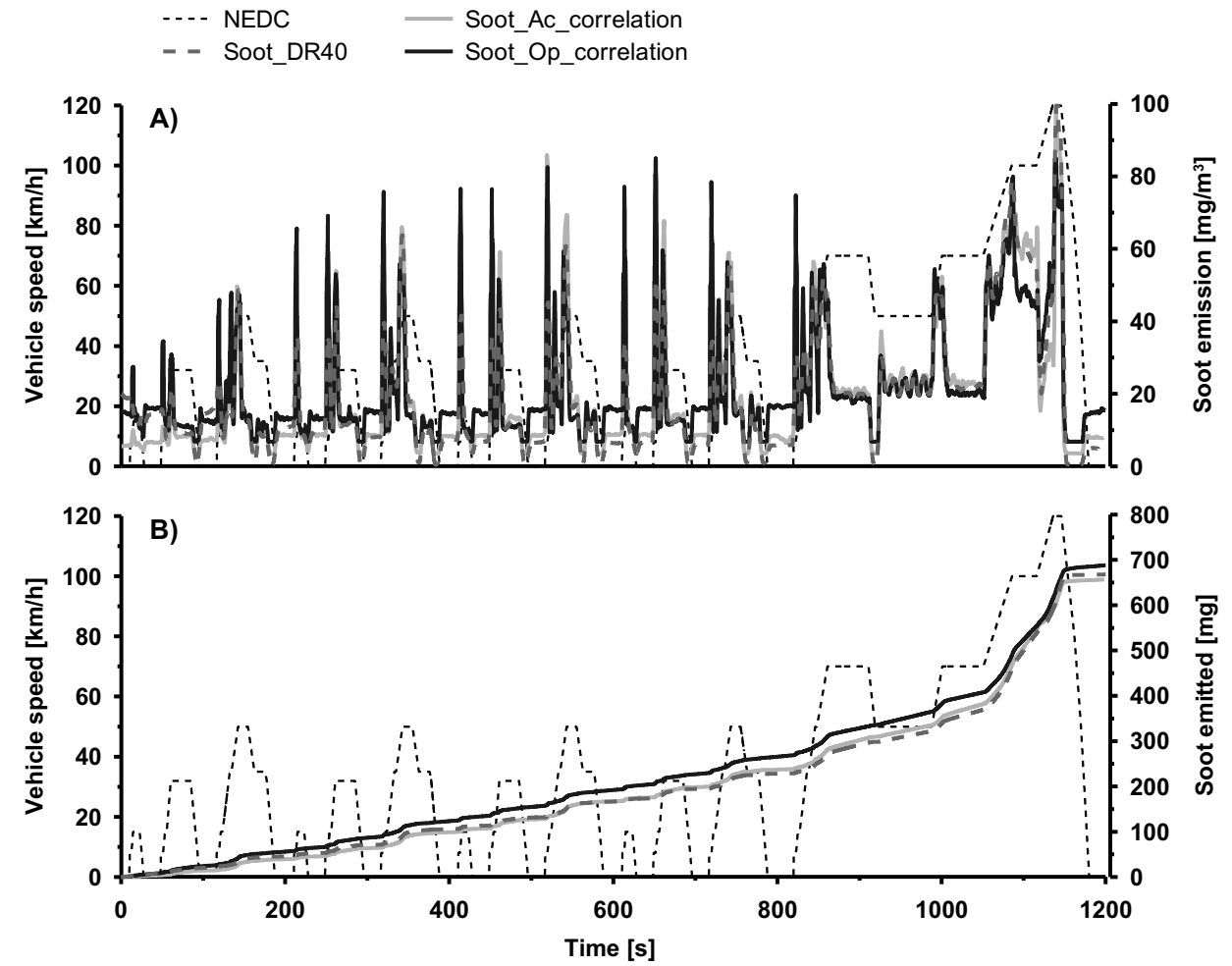

Figure 13. Evaluation of porposed correlation during a NEDC. 